\title{
Derived Biobased Catalyst from the three Agro Wastes Peel Powders for the Synthesis of Biodiesel from Luffa Cylindrical, Datura Stramonium, and Lagenaria Siceraria Oil Blend: Process Parameter Optimization
}

\author{
Adepoju T. F. ${ }^{1 *}$, Ukpong A. A. ${ }^{2}$ and Jimoh R. 0. ${ }^{3}$ \\ ${ }^{1}$ Chemical Engineering Department, Federal University Otuoke, Yenegoa, Bayelsa State, Nigeria \\ ${ }^{2}$ Chemical/Petrochemical Engineering Department, Akwa-Ibom State University, Nigeria \\ ${ }^{3}$ Department Chemical and Geological Sciences, Faculty of Natural Sciences, Al-Hikmah University, Nigeria \\ *Corresponding author: Adepoju TF, Chemical Engineering Department, Federal University, Otueke, Bayelsa State, Nigeria. P.M.B \\ 126, Yenagoa, Nigeria
}

ARTICLE INFO

Received: 㓞 December 02, 2021

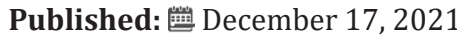

Citation: Adepoju TF, Ukpong AA, Jimoh RO. Derived Biobased Catalyst from the three Agro Wastes Peel Powders for the Synthesis of Biodiesel from Luffa Cylindrical, Datura Stramonium, and Lagenaria Siceraria Oil Blend: Process Parameter Optimization. Biomed J Sci \& Tech Res 40(4)-2021. BJSTR. MS.ID.006483.

Keywords: Biodiesel; Statistical Analysis; Heterogeneous Catalyst; Calcination; API Gravity Ratio; Green Waste Peels

\begin{abstract}
In a bid to replace fossil fuel and developed an ecofriendly based catalyst for the synthesis of biodiesel, this study developed a novel heterogeneous based catalyst from the mixture of Cucurbita pepo, Musa acuminate and Citrullus lanatus peels powders. The developed mixed catalyst was calcined at a temperature of $650 \mathrm{oC}$ for $3 \mathrm{~h}$ and applied for the synthesis of biodiesel from Luffa cylindrical, Datura stramonium, and Lagenaria siceraria oilseeds. The strength of the basicity of the calcined mixed powder (CMP) catalyst was tested by the catalyst reusability test. Results showed the synthesized catalysts produced high $\mathrm{CaO}$ of $62.83 \%, 65.50 \%, 58.67 \%$, and $75.65 \%$ for calcined Cucurbita pepo, Musa acuminate, Citrullus lanatus peels and the mixed catalyst powders. The blend ratio of 29:50:21 obtained, produced low viscous and high volatile oil used for successful transesterification. Maximum experimental biodiesel yield of 97.20 (\%wt.) was obtained, but the statistical analysis predicted a biodiesel yield of 96.63 (\% wt.) at the reaction time of $80 \mathrm{~min}$, the CMP amount of $3.53(\mathrm{~g})$, the reaction temperature of $90 \mathrm{oC}$, and the $\mathrm{CH}_{3} \mathrm{OH} / \mathrm{OMR}$ of $1: 9(\mathrm{ml} / \mathrm{ml})$, at the desirability of $95.10 \%$. This value was validated in triplicate, an average mean value of 96.50 (\% wt.) was obtained. Analysis of variance (ANOVA) test confirmed the variables were highly significant with $\mathrm{p}$-value $<0.0001$. Catalyst reusability test showed a significant decrease in the $5^{\text {th }}$ and the $6^{\text {th }}$ cycle; hence, the test was stopped at the end of the $4^{\text {th }}$ cycle. The produced biodiesel properties conform to the recommended standard. The study concluded that the derived heterogeneous catalyst successfully transformed the blended oil to biodiesel, and the developed catalyst was sustainable.
\end{abstract}

\section{Introduction}

Over-dependence on petroleum reserves for the supply of energy, increasing demand for energy, price volatility of fossil fuel, the monopoly in the crude oil market, energy crisis associated with technological advancement are indicators that the current quantity will not meet the mandate with time [1,2]. Therefore, countries (EU, Spain, North America, South America, China, Brazil, India, Argentina, Australia, Canada, Cuba, Colombia, France, Ghana, Kenya, Sweden, Singapore, USA, UK, Zimbabwe, Peru, Pakistan, 
Italy, Japan, Malaysia, Mali, Mexico, Iran, Ireland, Norway, Germany, etc.) around the globe have shifted attention to biodiesel due to its excellent environmental attributes, sustainability attributes, biodegradability, non-toxic, readily available, and reduction or elimination of over-dependence on fossil fuel [3-6]. Meanwhile, biodiesel potential feedstocks come from first generation biodiesel feedstocks, which associated with the use of edible vegetable oil (beniseed oil, soyabean oil, corn oil, canola oil, palm oil, sunflower oil, coconut oil, olive oil, linseed oil, peanut oil, corn oil, papaya oil, etc.), the second generation biodiesel feedstocks, which make use of non-edible vegetable oil and animal fat (Jatropha curcus oil, pongamia pinnata oil, waste cooking oil, yellow oleander oil, cotton oil, grease, tallow, rapeseed, castor oil, karanje oil, neem oil, fish fat, pig fat, rubber seed oil, etc.), and the third generation biodiesel feedstocks, which involve the use of microalgae, algae, fungi, bacteria, latexes [5,7-15]. Nevertheless, exploiting firstgeneration biodiesel feedstock leads to a major problem especially in the present world of food shortage [16]. On the other hand, the use of third generation biodiesel feedstock requires a large amount of water for algae productivity, significant fertilizer for algae growth, high production cost using current technology, the long time needed for conversion to biofuel, contenders with regional suitability issues, lack of energy-efficient product, variations in the biofuel quality, and monoculture issue. Therefore, non-edible feedstocks in second-generation biodiesel feedstock are the only secure and viable future for all through biofuel production.

Meanwhile, it has been reported that the use of mix/blend oil tends to improve the yield and the quality of biodiesel; hence, researchers have reported the use of different blend ratios of oil for biodiesel synthesis. Khalil, et al. [17] reportedly the used oil blend ratio of 40:60 for rubber seed oil and palm oil, with $\mathrm{NaOH}$ as a base catalyst. The study reported by Qiu, et al. [18] adopted a ratio of 50:50 for the mixture of soybean and rapeseed oil with $\mathrm{NaOH}$ as a base catalyst. Milano, et al. [19], combined cooking with Calophyllum inophyllum oil in the ratio of $75: 25$, with $\mathrm{KOH} f$ as a base catalyst, while Hadiyanto, et al. [20] combined waste cooking with castor oil in the ration of 1:0,1:2, and 2:1, respectively. Falowo, et al. [21], reported a blend of Neem and rubber oil in a 60:40 ratio with a base catalyst developed from elephant-ear tree pod husk. The work recently reported by Falowo, et al. [22], adopted the ternary blend ratio for Honne-Rubber-Neem oil, with mixed catalyst from three agro wastes. Observation from the reports showed that only Falowo, et al. [21,22] used heterogeneous catalysts for the synthesis of biodiesel production via oil blend. This was due to the heterogeneous catalytic nature such as reusability, recyclability, less water usage, non-toxic, low cost, eco-friendly, and high purity of by-product over the use of homogeneous catalysts $(\mathrm{NaOH} / \mathrm{KOH})$ $[16,23,24]$. To the author's awareness so far, no single report on the use of the API gravity ratio has been reportedly used for oil blend for biodiesel synthesis. Also, no report has ever derived a based catalyst from the mixture of three green wastes of Cucurbita pepo, Musa acuminate, and Citrullus lanatus unripe peels for catalytic application. Literature survey showed that the unripe Cucurbita pepo peels contain $27.85 \%$ calcium [25] while unripe Musa acuminate peels contained $57 \%$ calcium mineral [26], the calcium content found in Citrullus lanatus unripe peels was reported to be $43 \%$ [27]. Proper processing of the peels through drying, sieving, and calcination at a higher temperature above $550^{\circ} \mathrm{C}$ has been established as a way of improving the content of the calcium in the peels [28-30].

Hence, this work focusses on the synthesis of a mesoporous based catalyst from the mixture of Cucurbita pepo, Musa acuminate and Citrullus lanatus peels, applied it to transesterification of Luffa cylindrical - Datura stramonium - Lagenaria siceraria oil blend to biodiesel. Detail characterization of the catalysts developed was carried out using Scanning Electron Microscopy (SEM), Fourier Transforms Infrared Spectroscopy (FTIR), X-ray Diffraction Analysis (XRD), X-ray Diffractometer (XRD), and Brunauer-EmmettTeller (BET-adsorption) to determine its catalytic potential. Process optimization of transesterification of oil to biodiesel was carried out via response surface methodology (RSM). The quality of biodiesel was determined, and the results were compared with ASTM D6751 and EN 14214 biodiesel recommended standard.

\section{Materials and Methods}

\section{Materials}

Matured, Luffa cylindrical, Datura stramonium, Lagenaria siceraria seeds were collected from the nearby location around the rural house, Omu-Aran, Kwara State with proper permission obtained from the landowner in Nigeria. The seeds were separated from the husks by sundried for two weeks (14 days), and then oven-dried to a constant weight. The husk Datura stramonium has started splitting even before oven dried. The separated dried seeds were further obtained purely by winnowing and then milled into powders of $0.30 \mathrm{~mm}$ particle sizes, kept in separate cleaned containers for further processing (oil extraction). Cucurbita pepo, Musa acuminate, and Citrullus lanatus peels were obtained from the fruits. The peels were washed with distilled water twice, sundried for five days (5 days), and then oven-dried in a DHG-910102 oven at $80^{\circ} \mathrm{C}$ for $2 \mathrm{~h}$ to achieved constant weight. The dried peels were milled into powders, separated into small particle sizes using a mesh strainer (mesh size: $125 \mathrm{~mm}-20 \mu \mathrm{m}$ ) to aid calcination. The fine sieved powders Cucurbita pepo peels powder (CPPP), Musa acuminate peels powder (MAPP) and Citrullus lanatus peels powder (CLPP) were kept in crucibles for further processing (Calcination/ thermal treatment). The seeds were identified by the Adepoju T. F., 
and the sample of the seeds have been deposited in Chemical and Petrochemical Laboratory 2, Akwa Ibom State University, Nigeria with a deposition number LC2019 for Luffa cylindrical, DS2019 for Datura stramonium and LS2019 for Lagenaria siceraria. All chemicals used were of analytical grades and need no further purification.

\section{Methods}

Oil Extraction: Oil extractions from the powders were carried out using solvent extraction in $1 \mathrm{~L}$ soxhlet extractor apparatus. Since the heating mantle was designed to handle three-Soxhlet extractors at once, mass extraction was carried out simultaneously The oils were extracted from Luffa cylindrical, Datura stramonium, Lagenaria siceraria powders using n-hexane as the solvent. The procedures were as follows: the powders were put in a muslin bag and inserted in a Soxhlet extractor condenser with n-hexane at the round bottom flask placed on the heating mantle. The reaction temperature was monitored at $70^{\circ} \mathrm{C}$ for a complete extraction period $(1 \mathrm{~h})$. At the end of the reaction, the residual cakes were kept as a supplement for animal feeds while excess n-hexane in oils was recovered using the rotary evaporator. The clean oils Luffa cylindrical oil (LCO), Datura stramonium oil (DSO), and Lagenaria siceraria (LSO) were collected and kept in separate containers for further treatment. Oil qualities were ascertained by determining the physical, chemical, and other properties of the oils through AOAC (1997) standard test methods.

Oil Blend: The blend is the acts of mixing two or more substances, either miscible or non-miscible. For oils proper mix, it is worthwhile to know that the action of oil always increased by mixing several oils, nevertheless, the order in which the oil must be mixed must be factor properly. Lighter oil with smaller molecules will produce less viscous oils with high volatility, but heavier oil and larger molecules produce high viscous oils with low volatility. Hence, to obtain a low viscous, low density, and high volatile oil, there is a need for oil mix in an accurate blend ratio to increase the synergistic effect within the blended oil. One must know the nature (heavy or light) of the oil before mixing. The extracted oil is defined with API gravity, API gravity greater than 10 indicated lighter oil and the oil floats on water, the value of API gravity lesser than 10 indicated heavier oil, and the oil sinks on water. The API gravity of oil is calculated using Eq. (1) [31].

$$
\text { API gravity }=\frac{141.5}{\text { Specific gravity }}-131.5
$$

Oil Blend via API Gravity Estimate: The API gravity of the oils was estimated based on the specific gravity of the oil. The total API gravity of the oils was obtained from the API gravity of the oils obtained, the mix ratio of oil was computed using the mathematically derived Eq. (2), and the oil was properly mixed by heating at $50 \mathrm{oC}$ on a magnetic shaker for $30 \mathrm{~min}$.

$$
\text { Mix ratio }=\frac{\text { API gravity }}{\text { Total API gravity }} \times 100
$$

\section{Catalyst's Calcination and Characterization}

The fine powders (CPPP, MAPP, CLPP), with mixed powder $(30 \mathrm{~g} \mathrm{CPPP}+30 \mathrm{~g}$ MAPP $+30 \mathrm{~g}$ CLPP) (MP) were calcined at 650 ${ }^{\circ} \mathrm{C}$ for $3 \mathrm{~h}$ to obtain the powdered catalysts [6]. After cooling, the powdered were characterized using scanning electron microscopy (SEM), to examine the surface morphology of the catalysts, energy dispersive spectroscope (EDS) to determine the elemental analysis of the samples and the quantitative composition of the catalysts, $\mathrm{X}$-ray diffractometer (XRD) equipped with Kó and $\mathrm{Cu}$ radiation source, accelerated at $20 \mathrm{~mA}$ and $30 \mathrm{kV}$, to establish the angular scanning electron performed in the range of $20^{\circ}<2 \theta<80^{\circ}$ at speed of $2^{\circ} \mathrm{C} \mathrm{min}{ }^{-1}$, Fourier transform infrared spectroscopy (FTIR), to check the presence of functional group and verify the presence of characteristic absorption bands of major elements present. The surface area and the basicity of the catalysts were examined using BET isothermal adsorption and the Hammett indicator method [32].

\section{Synthesis of Biodiesel}

The mixed oil $(29: 50: 21)$ free fatty acid $(F F A=0.82<1.5)$ was within the moderate value for transesterification of oil to biodiesel [33]. Therefore, transesterification of mixed oil (MO) to biodiesel through methanolysis of the mixed powder (MP) was carried out using the procedure earlier reported by Adepoju, et al. [29] with few modifications. A three-necked-reactor was used to carry out biodiesel production, four factors with five-level were considered viz. reaction time, calcined mixed powder (CMP) amount, reaction temperature, and methanol/oil molar ratio ( $\mathrm{MeOH} / \mathrm{OMR}$ ). The MO was preheated at $60^{\circ} \mathrm{C}$ for $30 \mathrm{~min}$, a known CMP was added to 40 $\mathrm{ml}$ of methanol in a $250 \mathrm{ml}$ flask, heated at $65^{\circ} \mathrm{C}$ for $20 \mathrm{~min}$ in a magnetic shaker, the insoluble methanolic-catalyst was transferred into the preheated oil in the reactor, and the reaction was monitored at a particular temperature until the reaction reach completion. At the end of the reaction, the solid phase catalyst was separated by decantation and the biodiesel phase was separated from the ethanol phase by separating funnel. The leached catalyst in the biodiesel was removed by washing with a solution (containing a mixture of $2.0 \mathrm{~g}$ of $\mathrm{NaCO}_{3}$ and $40 \mathrm{ml}$ ethanol thermally heated for 2 h) under agitation. The mixture was filtered, washed with distilled water three times before the separation of biodiesel through gravity settling was carried out. The washed biodiesel was then dried over anhydrous $\mathrm{Na}_{2} \mathrm{SO}_{4}$ and then separated by filtration to obtain pure biodiesel. These processes were repeated based on experimental runs generated by response surface methodology experimental design. 
Experimental Design for Biodiesel Synthesis and Its Statistical Analysis: The four-level-five-factors used for biodiesel experimental designed with the respective units are presented in Table 1. A central composite design (CCD) was used which contains 24 non-center and 6 center points with high and low center factors, the design is a full type with 2 alpha and 1 block. A total of 30 experimental runs were obtained with central composite design replication occurred for every categorical combination. For analysis through the statistical approach, the model for response surface (biodiesel) and the interaction (variable factors) was evaluated by mean of fit summary. The model order, significant effects, and desired terms were evaluated by model effects. ANOVA was used to analyze the chosen model and view results, while diagnostic, evaluate the model fit, and also the transformation choice with the graph to interpret and evaluates the model. Moreover, process optimization was established by determining the probability value (p-value), the f-value (factor value), the degree of freedom (df), and the variance inflation factor (VIF), respectively. Linear regression parameters were obtained through evaluation of the coefficient of determination the predicted coefficient of determination, the adjusted coefficient of determination, and the adequate precision (Adeq. Prec.) to confirm the model suitability. Meanwhile, to show the relationship between two input variables and one output, three dimensional and contour plots prove to be the best representative of the correlation (Adepoju et al., 2016). The second-order polynomial model equation that further explains the relationship between biodiesel yield and the independent variables is mathematically expressed as Eq. (3).

$$
\text { Biodiesel }(w t . \%)=P_{0}+\sum_{i=1}^{k} p_{i} x_{i}+\sum_{i=1}^{k} p_{i i} x_{i}^{2}+\sum_{i<j}^{k} p_{i j} x_{i} x_{j}+\varepsilon
$$

Where FAME is the response (biodiesel) in percentage, $\mathrm{P}_{-} 0$ is the intercept, $P_{-} i$ is the linear coefficient, $P_{-}$ii is the interaction coefficient, $P_{-}$ij is the quadratic coefficient terms, $X_{-} i$ [ and $X \rrbracket_{-} j$ are the four factors and $\epsilon$ is the residual error.

Table 1: Experimental design for biodiesel production.

\begin{tabular}{|c|c|c|c|c|c|c|c|}
\hline \multirow{2}{*}{ Variables } & \multirow{2}{*}{ Units } & \multirow{2}{*}{ Symbol } & \multicolumn{5}{|c|}{ Levels } \\
\cline { 3 - 8 } & & & $\mathbf{- 2}$ & $\mathbf{- 1}$ & $\mathbf{0}$ & $\mathbf{1}$ & $\mathbf{2}$ \\
\hline Reaction time & $(\mathrm{min})$ & $\mathrm{X} 1$ & 60 & 65 & 70 & 35 & 80 \\
\hline CMP amount & $(\mathrm{g})$ & $\mathrm{X} 2$ & 2 & 2.5 & 3 & 75 & 80 \\
\hline Reaction temp. & $(\mathrm{oC})$ & $\mathrm{X} 3$ & 60 & 65 & 70 & 7 & 8 \\
\hline MeOH/OMR & $(\mathrm{ml} / \mathrm{ml})$ & $\mathrm{X} 4$ & 5 & 6 & & 9 \\
\hline
\end{tabular}

Biodiesel Quality Characterization: The effectiveness and industrial application of biodiesel produce depend solely on its quality such as moisture content, density, viscosity, mean molecular mass, peroxide value, iodine value, saponification value, cetane number, higher heating value, API gravity, and diesel index. These properties were determined using AOAC, (1997) standard methods; the results were compared with biodiesel recommended standards $[34,35]$. All methods were performed in accordance with the relevant guidelines and regulations governing institutional, national, and international guidelines and legislation including the collection of plant material, the Experimental research and field studies on plants/seeds.

\section{Results and Discussion}

\section{Extracted Oils Qualities and It Mixed Ratio}

Table 2 showed the results of the qualities of the oils and the mixed oil obtained. From the table, it was observed that the specific gravity of the LSO (0.95) was highest, followed by the LCO (0.910), and then DSO (0.820). The higher the specific gravity, the lower the API gravity of the oil, and such oil tends to be less light in nature. The extracted oils were light oils with low free fatty acid value and low moisture content. The iodine value and the viscosity of the LSO
(98.02 $\mathrm{g} \mathrm{I}_{2} / 100 \mathrm{~g}$ oil; $4.10 \mathrm{~mm}^{2} / \mathrm{s}$ ) appear higher than the value of LCO (96.50 $\mathrm{g} \mathrm{I}_{2} / 100 \mathrm{~g}$ oil; $4.10 \mathrm{~mm}^{2} / \mathrm{s}$ ) and DSO (72.32 $\mathrm{g} \mathrm{I}_{2} / 100 \mathrm{~g}$ oil; $2.12 \mathrm{~mm}^{2} / \mathrm{s}$ ). However, the acid value of the LCO (4.50 mg KOH/g oil) is higher than the acid value of LSO (1.84 mg KOH/g oil) and DSO (1.43 $\mathrm{mg} \mathrm{KOH/g}$ oil), these showed that the LCO is non-edible oil. The API gravity of DSO (50) is greater than the values obtained for LCO (29) and LSO (21) which accounted for an oil mixed ratio of 29:50:21 for LCO: DSO: LSO. This mixed ratio produced oil with moderate FFA and of low density used for biodiesel production (transesterification).

\section{Catalyst Characterization and Elemental Analysis}

Scanning Electron Microscopy (SEM): Figure 1a showed the result of SEM images of morphological characteristics of the calcined mixed powder (CMP) at a different magnification of $1000 \mathrm{x}$ and 500x performed in the range of $20^{\circ}<2 \theta<80^{\circ}$ at speed of $2^{\circ} \mathrm{C} /$ min. The decomposed images after calcination at a temperature of $650^{\circ} \mathrm{C}$ for $3 \mathrm{~h}$ indicated non-uniform sizes with diverse shapes and slightly rough surface with cracks. This observation implied thermal treatment degrades organic substances in the mixed powder (MP) and also transforms the calcium carbonate $\left(\mathrm{CaCO}_{3}\right)$ to the calcium oxide ( $\mathrm{CaO})$, owing to the gaseous form of carbon dioxide $\left(\mathrm{CO}_{2}\right)$ which appears more porous, brittle and easy to ground. 
Table 2: Qualities of the oils and API gravity mixed ratio.

\begin{tabular}{|c|c|c|c|c|}
\hline Properties/Oils & LCO & DSO & LSO & Total API gravity \\
\hline Viscosity @ 40oC/ ( $\left.\mathrm{mm}^{2} / \mathrm{s}\right)$ & 3.6 & 2.12 & 4.1 & \\
\hline Peroxide value (meq $\mathrm{O}_{2} / \mathrm{kg}$ oil) & 15.4 & 6.24 & 6.31 & \\
\hline Saponification value (mg KOH/g oil) & 194 & 178.46 & 201 & \\
\hline Iodine value (g I2/100g oil) & 96.5 & 72.32 & 98.02 & \\
\hline Moisture content (\%) & 0.015 & 0.015 & 0.015 & \\
\hline Acid value (mg KOH/g oil) & 4.5 & 1.43 & 1.84 & \\
\hline$\% \mathrm{FFA}$ & 2.25 & 0.715 & 0.92 & \\
\hline Specific gravity & 0.91 & 0.82 & 0.95 & \\
\hline API gravity & 23.99 & 41.06 & 17.45 & 82.5 \\
\hline Heavier/Lighter oil & Lighter oil & Lighter oil & Lighter oil & \\
\hline Mixed ratio & 0.291 & 0.498 & 0.211 & \\
\hline$\%$ Mixed ratio & 29 & 50 & 21 & \\
\hline
\end{tabular}

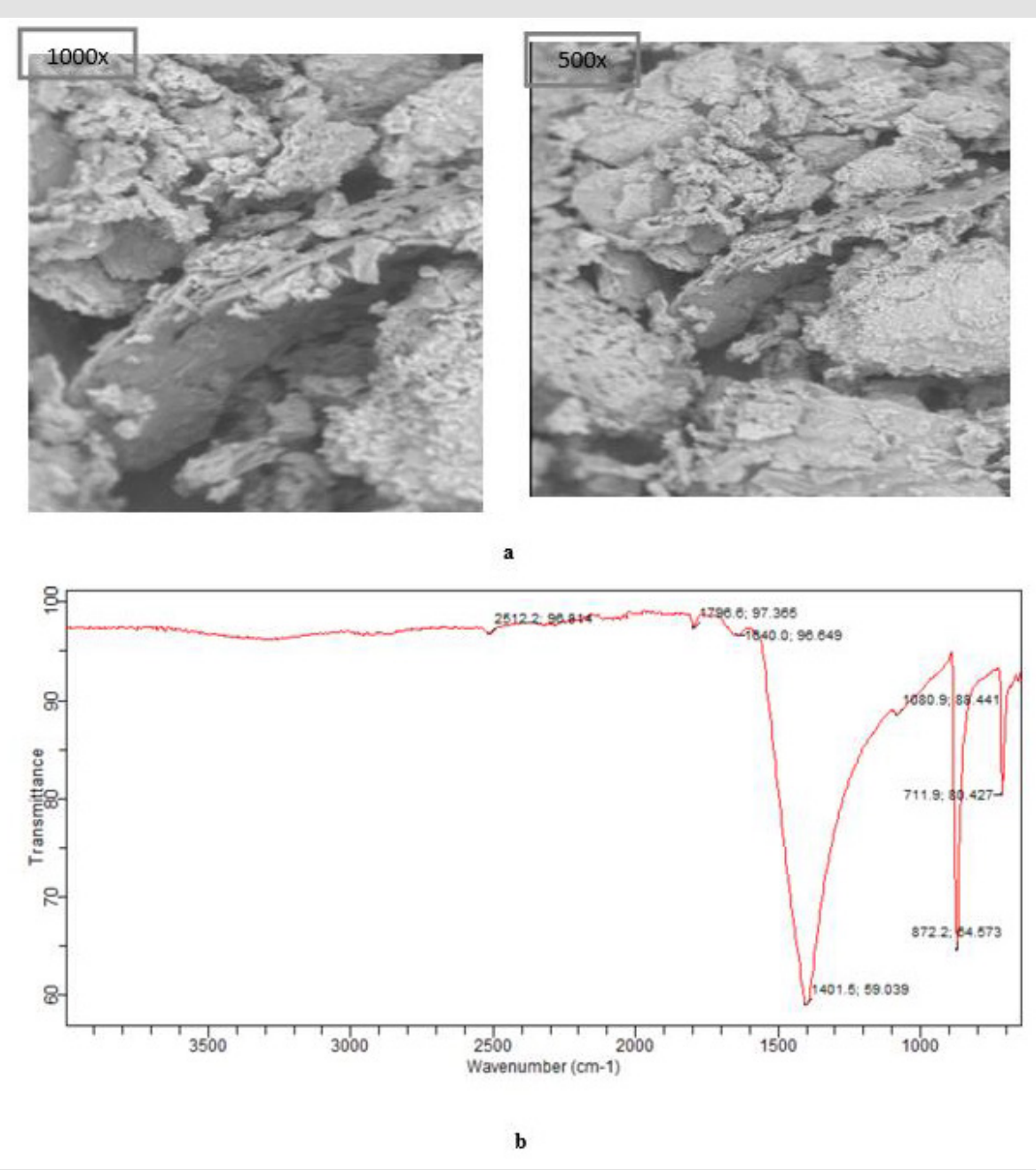

Figure 1:

a. SEM image of CMP at different magnifications.

b. FTIR analysis of CMP at $650 \mathrm{oC}$ for $3 \mathrm{~h}$. 
Fourier-Transform Infrared Spectroscopy (FTIR): Figure 1b shows the FTIR spectra of CMP, distinct peaks were noticed at 711.9, $872.2,1080.9,1401.5,1640.0,1796.6$, and 2512.2, respectively. The band at $1401.5 \mathrm{~cm}^{-1}$ represents bending vibration of the $\mathrm{O}-\mathrm{Ca}-\mathrm{O}$ group while the band at 771.9 - 1080.9 represents a stretch of $\mathrm{CO}_{32}$ molecules to higher energy value $[3,36]$. The spectrum stretches from $1640.0-2512.2 \mathrm{~cm}^{-1}$ indicated the presence of functional groups such as $\mathrm{O}-\mathrm{H}, \mathrm{C}-\mathrm{H}$ for $\mathrm{sp}^{3}$ carbon, $\mathrm{C}=\mathrm{O}$ for $\mathrm{sp}^{2}$ carbon, $\mathrm{CHO}$, and $\mathrm{N}-\mathrm{H}$ bond. Nevertheless, the undistorted assembly of CMP catalyst transformed into a spongy like structure signifies that calcination of the mixed powder at a temperature of $650^{\circ} \mathrm{C}$ was appropriate for a complete transformation of $\mathrm{CaCO}_{3}$ to $\mathrm{CaO}$ [16]. This observation could be attributed to the presence of functional groups present in the fruits during the growth period which occurred as a result of carbon growth inhibition.

Brunauer-Emmett-Teller (BET): Table 3 represents the properties of the catalysts indicating the BET surface, total pore volume, basicity, and percentage of $\mathrm{CaO}$ converted through $\mathrm{N}_{2}$ adsorption-desorption isotherm Brunauer-Emmett-Teller (BET) analysis. Observation from the results shows the calcined mixed powder (CMP) has a high basic site than other calcined catalysts (CMAPP, CCLPP, and CCPPP) owing to the high CaO (75.65\%) obtained during analysis in the calcined powder. The basic site density obtained for CMAPP (158. $00 \mu \mathrm{mole} / \mathrm{m}^{2}$ ) was higher than that of CCLPP (120.00 $\mu \mathrm{mole} / \mathrm{m} 2)$, but the value obtained for CCPPP $\left(157.80 \mu \mathrm{mole} / \mathrm{m}^{2}\right)$ is approximately the same with CMAPP. However, the basic site density of the CMP $\left(160.83 \mu \mathrm{mole} / \mathrm{m}^{2}\right)$ was the highest which produced the highest biodiesel yield during transesterification. The table also reflects the result of biodiesel yields, at the same process conditions, each catalyst was tested based on the $\mathrm{CaO}$ yield of the calcined powders (ССPPP: 62.83\%; CMAPP: 65.50\%; CCLPP: 58.67 and CMP: 75.65\%), the yields of biodiesel based on the nature of catalyst showed the three calcined catalysts have a basic site for conversion of oil to biodiesel (83.50, $88.75,80.32$ (\%wt.)), but the mixed calcined catalyst produced highest biodiesel yield ( $96.50 \%$ wt.), due to the percentage of $\mathrm{CaO}$ in the catalyst and high basic site. Hence, the catalysts could be an economic viable promising source for $\mathrm{CaO}$ catalyst production for industrial applications.

Table 3: BET-adsorption and XRD analysis of calcined catalysts at $650 \mathrm{oC}$ for $3 \mathrm{~h}$.

\begin{tabular}{|c|c|c|c|c|c|c|c|c|}
\hline Catalysts & $\begin{array}{l}\text { N2-AA } \\
\left(m^{2} g^{-1}\right)\end{array}$ & $\begin{array}{l}\text { TPVx10-3 } \\
\left(\mathrm{cm}^{3} \mathrm{~g}^{-1}\right)\end{array}$ & $\% \mathrm{CaO}$ & \multicolumn{2}{|c|}{$\begin{array}{c}\left.\text { BS }\left(\mu \text { mole }^{-1}\right)^{-1}\right) \\
400<\text { BS }<500>500\end{array}$} & TBS & $\begin{array}{c}\text { BSD }(\mu \mathrm{mole} / \\
\left.\mathbf{m}^{2}\right)\end{array}$ & Bio (wt.\%) \\
\hline ССРРР & 0.9 & 5 & 62.83 & 32 & 110 & 142 & 157.8 & 83.5 \\
\hline CMAPP & 1 & 5 & 65.5 & 38 & 120 & 158 & 158 & 88.75 \\
\hline CCLPP & 1.1 & 5 & 58.67 & 26 & 106 & 132 & 120 & 80.32 \\
\hline CMP & 1.2 & 5 & 75.65 & 45 & 148 & 193 & 160.83 & 96.5 \\
\hline
\end{tabular}

Optimization of Transesterification Mixed Oil to Biodiesel

Experimental Results Analysis: Table 4 shows the coded experimental conditions, the experimental biodiesel yield, the predicted, and the residual values of the 30 standard runs generated by CCD. The table showed the maximum experimental yield of 97.20 (\% wt.) at runs 18, while the minimum yield was obtained at runs 19 with a value of 85.66 (\% wt.). Based on statistical analysis, the results were transformed into a fit summary, quadratic model, analysis of variance evaluation, diagnostics and graphs modeling, the predicted biodiesel yield of 96.63 (\% wt.) was obtained at the following condition: reaction time of $80 \mathrm{~min}$, CMP amount of $3.53 \mathrm{~g}$ ), reaction temperature of $90 \mathrm{oC}$, and $\mathrm{CH} 3 \mathrm{OH} / \mathrm{OMR}$ of 9:1 $(\mathrm{ml} / \mathrm{ml})$, at the desirability of $95.10 \%$. This value was validated in triplicate, an average mean value of 96.50 (\% wt.) was obtained which was close to the predicted value. The result proved that the methanolysis of CMP for the transesterification of mixed oil was successful.

Table 4: Coded factors, experimental, predicted biodiesel yield, and residuals values.

\begin{tabular}{|c|c|c|c|c|c|c|c|}
\hline Std Runs & $\mathbf{X}_{\mathbf{1}}(\mathbf{m i n})$ & $\mathbf{X}_{\mathbf{2}}(\mathbf{g})$ & $\left.\mathbf{X}_{\mathbf{3}} \mathbf{( o C}\right)$ & $\left.\mathbf{X}_{\mathbf{4}} \mathbf{( m l} / \mathbf{m l}\right)$ & Exp. Bio (\% wt.) & Pred. Bio (\% wt.) & Residual \\
\hline 1 & 65 & 2.5 & 65 & 6 & 88.8 & 88.77 & 0.029 \\
\hline 2 & 75 & 2.5 & 65 & 6 & 89.6 & 89.64 & -0.038 \\
\hline 3 & 65 & 3.5 & 65 & 6 & 91.2 & 91.19 & 0.012 \\
\hline 4 & 75 & 3.5 & 65 & 6 & 90.9 & 90.85 & 0.046 \\
\hline 5 & 65 & 2.5 & 75 & 6 & 87.7 & 87.67 & 0.029 \\
\hline 6 & 75 & 2.5 & 75 & 6 & 92.1 & 92.09 & 0.012 \\
\hline 7 & 65 & 3.5 & 75 & 6 & 89.4 & 89.54 & -0.14 \\
\hline 8 & 75 & 3.5 & 75 & 6 & 92.8 & 92.75 & 0.046 \\
\hline
\end{tabular}




\begin{tabular}{|c|c|c|c|c|c|c|c|}
\hline 9 & 65 & 2.5 & 65 & 8 & 89.1 & 89.17 & -0.071 \\
\hline 10 & 75 & 2.5 & 65 & 8 & 89.9 & 89.69 & 0.21 \\
\hline 11 & 65 & 3.5 & 65 & 8 & 93.5 & 93.44 & 0.062 \\
\hline 12 & 75 & 3.5 & 65 & 8 & 92.7 & 92.75 & -0.054 \\
\hline 13 & 65 & 2.5 & 75 & 8 & 89.7 & 89.67 & 0.029 \\
\hline 14 & 75 & 2.5 & 75 & 8 & 93.7 & 93.74 & -0.038 \\
\hline 15 & 65 & 3.5 & 75 & 8 & 93.4 & 93.39 & 0.012 \\
\hline 16 & 75 & 3.5 & 75 & 8 & 96.3 & 96.25 & 0.046 \\
\hline 17 & 60 & 3 & 70 & 7 & 93.6 & 93.56 & 0.042 \\
\hline 18 & 80 & 3 & 70 & 7 & 97.2 & 97.29 & -0.092 \\
\hline 19 & 70 & 2 & 70 & 7 & 85.6 & 85.66 & -0.058 \\
\hline 20 & 70 & 2 & 70 & 7 & 90.6 & 90.59 & 0.008 \\
\hline 21 & 70 & 3 & 60 & 7 & 89.7 & 89.78 & -0.075 \\
\hline 22 & 70 & 3 & 80 & 7 & 92.2 & 92.18 & 0.025 \\
\hline 23 & 70 & 3 & 70 & 5 & 88.7 & 88.68 & 0.025 \\
\hline 24 & 70 & 3 & 70 & 9 & 92.5 & 92.58 & -0.075 \\
\hline 25 & 70 & 3 & 70 & 7 & 93.5 & 93.5 & 0 \\
\hline 26 & 70 & 3 & 70 & 7 & 93.5 & 93.5 & 0 \\
\hline 27 & 70 & 3 & 70 & 7 & 93.5 & 93.5 & 0 \\
\hline 28 & 70 & 3 & 70 & 7 & 93.5 & 93.5 & 0 \\
\hline 29 & 70 & 3 & 70 & 7 & 93.5 & 93.5 & 0 \\
\hline 30 & 70 & 3 & 70 & 7 & 93.5 & 93.5 & 0 \\
\hline
\end{tabular}

ANOVA and Fits Statistic: Table 5 shows the analysis of variance (ANOVA) for the response surface quadratic model and the Fit statistics. Observation from the table shows that the Model F-value of 1765.55 with a degree of freedom (df) of 14, implies the model is significant with prob value $>0.0001$. There is only a $0.01 \%$ chance that a "Model F-value" this large could occur due to noise. Meanwhile, values of "Prob > F" less than 0.05 show variable terms are significant. In this case, $\mathrm{X}_{1}, \mathrm{X}_{2}, \mathrm{X}_{3}, \mathrm{X}_{4}, \mathrm{X}_{12}, \mathrm{X}_{22}, \mathrm{X}_{32}, \mathrm{X}_{42}, \mathrm{X}_{1} \mathrm{X}_{2}, \mathrm{X}_{1} \mathrm{X}_{3^{\prime}}$ $\mathrm{X}_{1} \mathrm{X}_{4}, \mathrm{X}_{2} \mathrm{X}_{3}, \mathrm{X}_{2} \mathrm{X}_{4}$, and $\mathrm{X}_{3} \mathrm{X}_{4}$ were remarkable significant variable terms. The coefficient of determination is the correlation coefficient, also known as R-square,which allows it to display the degree of linear correlation between two variables. The value obtained in this study is high (99.94\%), indicate a high degree of correlation between the interacting variables. The "Pred. R-Squared" of $99.65 \%$ is in reasonable agreement with the "Adj R-Squared" of 99.88\%. The "Adeq Precision", which measures the signal to noise ratio. Usually, a ratio greater than 4 is desirable, the ratio of 188.58 obtained in the study specifies an adequate signal.The polynomial model quadratic equation that shows the relationship between the biodiesel yield and the four-variable factors is presented in Eq. (4).

The final equation in term of coded

$$
\begin{aligned}
& \text { Biodiesel }(\% w)=+93.50+0.93 X_{1}+1.23 X_{2}+0.63 X_{3}+0.97 X_{4}-0.03 X_{1} X_{2}+0.89 X_{1} X_{3}- \\
& 0.087 X_{1} X_{4}-0.14 X_{2} X_{3}+0.46 X_{2} X_{4}+0.40 X_{3} X_{4}+0.48 X_{1}^{2}-1.34 X_{2}^{2}-0.63 X_{3}^{2}-0.72 X_{4}^{2}
\end{aligned}
$$

Table 5: ANOVA and Parametric Data Fit.

\begin{tabular}{|c|c|c|c|c|c|c|}
\hline Source & Sum of Squares & df & Mean Square & F Value & Prob > F & Outcomes \\
\hline Model & 80.95 & 14 & 5.78 & 115.91 & $<0.0001$ & Significant \\
\hline $\mathrm{X}_{1}$ & 3.66 & 1 & 3.66 & 73.43 & $<0.0001$ & Significant \\
\hline $\mathrm{X}_{2}$ & 14.94 & 1 & 14.94 & 299.51 & $<0.0001$ & Significant \\
\hline $\mathrm{X}_{3}$ & 15.01 & 1 & 15.01 & 300.85 & $<0.0001$ & Significant \\
\hline $\mathrm{X}_{4}$ & 3.37 & 1 & 3.37 & 67.57 & $<0.0001$ & Significant \\
\hline $\mathrm{X}_{12}$ & 0.16 & 1 & 0.16 & 3.26 & 0.0925 & Not significant \\
\hline $\mathrm{X}_{22}$ & 0.47 & 1 & 0.47 & 9.36 & 0.0085 & Significant \\
\hline $\mathrm{X}_{32}$ & 14.83 & 1 & 14.83 & 297.3 & $<0.0001$ & Significant \\
\hline
\end{tabular}




\begin{tabular}{|c|c|c|c|c|c|c|}
\hline $\mathrm{X}_{42}$ & 0.6 & 1 & 0.6 & 11.93 & 0.0039 & Significant \\
\hline $\mathrm{X}_{1} \mathrm{X}_{2}$ & 1.3 & 1 & 1.3 & 26.05 & 0.0002 & Significant \\
\hline $\mathrm{X}_{1} \mathrm{X}_{3}$ & 2.69 & 1 & 2.69 & 53.92 & 0.0001 & Significant \\
\hline $\mathrm{X}_{1} \mathrm{X}_{4}$ & 0.11 & 1 & 0.11 & 2.25 & 0.1559 & Not significant \\
\hline $\mathrm{X}_{2} \mathrm{X}_{3}$ & 0.087 & 1 & 0.087 & 1.74 & 0.2078 & Not significant \\
\hline $\mathrm{X}_{2} \mathrm{X}_{4}$ & 22.56 & 1 & 22.56 & 452.29 & 0.0001 & Not significant \\
\hline $\mathrm{X}_{3} \mathrm{X}_{4}$ & 0.000025 & 1 & 0.000025 & 0.000501 & Significant \\
\hline Residual & 0.7 & 14 & 0.05 & - & Not significant \\
\hline Lack of Fit & 0.066 & 10 & 0.006639 & 0.042 & - & Not significant \\
\hline Pure Error & 0.63 & 4 & 0.16 & & & Significant \\
\hline Cor Total & 80.95 & 14 & 5.78 & & & \\
\hline Std. Dev. & 0.087 & R-Squared & 0.9994 & & & \\
\hline Mean & 91.73 & Adj R-Squared & 0.9988 & & & \\
\hline C.V. & 0.095 & Pred R-Squared & 0.9965 & & & \\
\hline PRESS & 0.66 & Adeq Precision & 188.58 & & & \\
\end{tabular}

Meanwhile, the positive and the negative coefficients in the equation are the direct measure of the influence of variables on the response value. In this equation, the variable $\mathrm{X}_{2}$ with a coefficient of 1.23 , $\mathrm{f}$-value $=4796.50$, with $\mathrm{p}$-value $<0.0001$ is the most significant variable among the second-order polynomial equation in Eqn. (4).

Graphical Plots: Furthermore, the relationship between the response variable (biodiesel) and the interactive variables $\left(\mathrm{X}_{1} \mathrm{X}_{2}\right.$, $\mathrm{X}_{1} \mathrm{X}_{3}, \mathrm{X}_{1} \mathrm{X}_{4}, \mathrm{X}_{2} \mathrm{X}_{3}, \mathrm{X}_{2} \mathrm{X}_{4}$, and $\mathrm{X}_{3} \mathrm{X}_{4}$ ) can be represented in contour and the three-dimensional plots as displayed in Figures 2a-2f. The observation from the graph shows Figure $2 \mathrm{e}$ has the highest mutual interaction between CMP amount and $\mathrm{MeOH} / \mathrm{OMR}$ on the response biodiesel yield. The mutual interactive effects between reaction time and $\mathrm{MeOH} / \mathrm{OMR}$ (Figure 2f) is higher than that observed in the interactive effects noticed between reaction time and reaction temperature (Figure $2 \mathrm{~b}$ ) on the response, but the interactive effects in Figure2c (MeOH/OMR and reaction temperature) is lesser than the interactive effects showed by Figure $2 b$, but higher than the interaction between CMP amount and reaction temperature (Figure 2d). Meanwhile, the least interactive effects were noticed in Figure 2a, which was the interaction between CMP amount and reaction time on response biodiesel produced. In all, there exist perfect interaction among the variables, which confirmed the variable factors considered in this study play an important role in biodiesel yield. The relationship between the predicted biodiesel and the experimental biodiesel yields as well as power transformation boxcox were as illustrated in Figures 3a \& 3b.

\section{Catalyst Reusability Test}

For catalyst purification and reusability analysis of the reaction mixture, a built-in heating system vacuum centrifuges operated at $3500 \mathrm{rpm}$ was used, the recovered catalyst was washed with alcohol to remove the impurity at the surface of catalyst that occurred during the transesterification. The alcoholic washed catalyst was oven-dried at $100^{\circ} \mathrm{C}$ for $1 \mathrm{~h}$ and then cooled to room temperature before reused. Nevertheless, the reactor wall accumulates a $0.15 \mathrm{~g}$ catalyst during the reaction, which tends to reduce the surface area and lowered catalyst activity. Hence, the need for catalyst reusability tests on catalytic activities. Figure 4 shows that the catalytic activities-maintained stability from the $1^{\text {st }}$ cycle to the $4^{\text {th }}$ cycle with little decreased from 93.6 (\% wt.) to 92.20 (\% wt.). However, there was significant decrease observed in $5^{\text {th }}$ and $6^{\text {th }}$ cycles $(89.7$ and $88.7 \% \mathrm{wt}$.), this can be associated to the continuous intermediate products formed during the reaction, such as monoglyceride and diglyceride, which obstructed the catalyst holes as well as water to oxygen reaction that occurred at the catalyst surface, which reduce the catalyst sensitivity. Hence, catalyst reusability was stopped after the $4^{\text {th }}$ cycle [37-39]. 

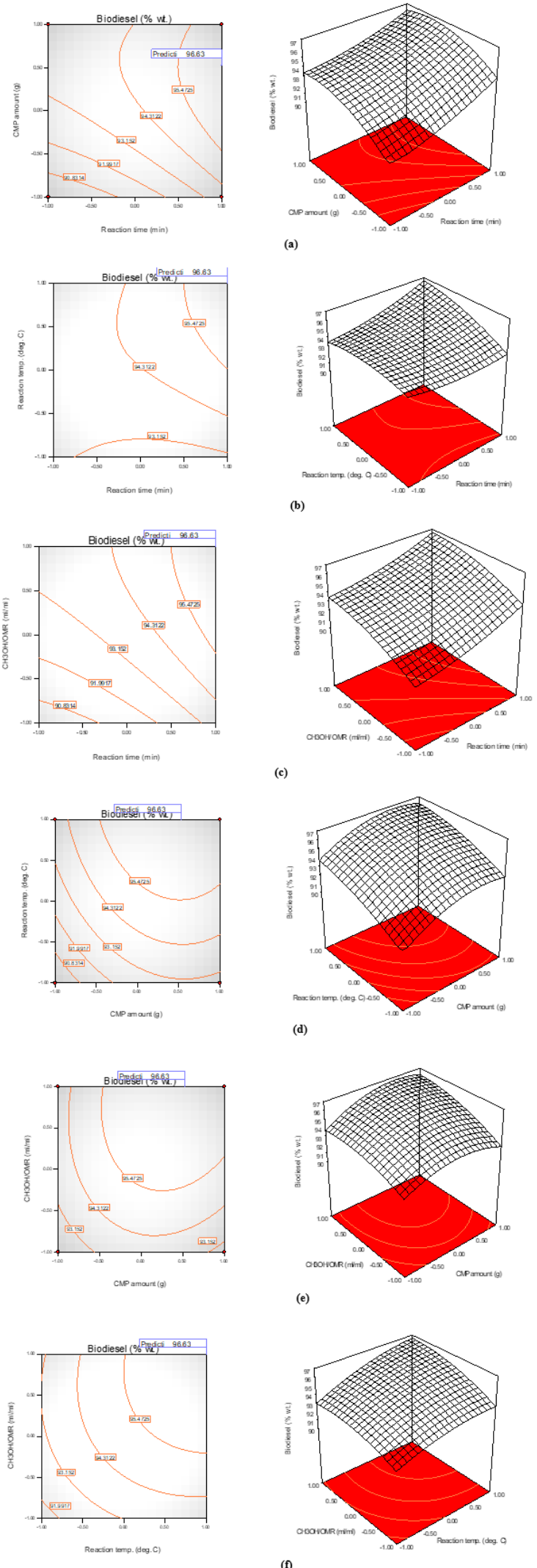

(f)

Figure 2: Contour and 3-D's Plots. 


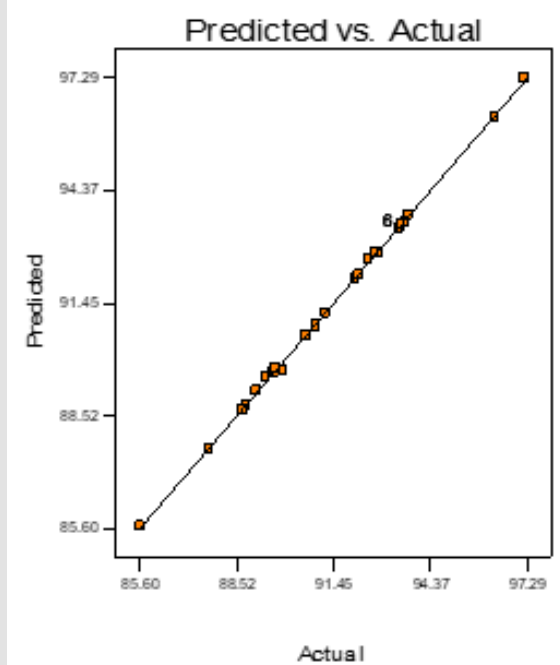

(a) Predicted Vs. Actual

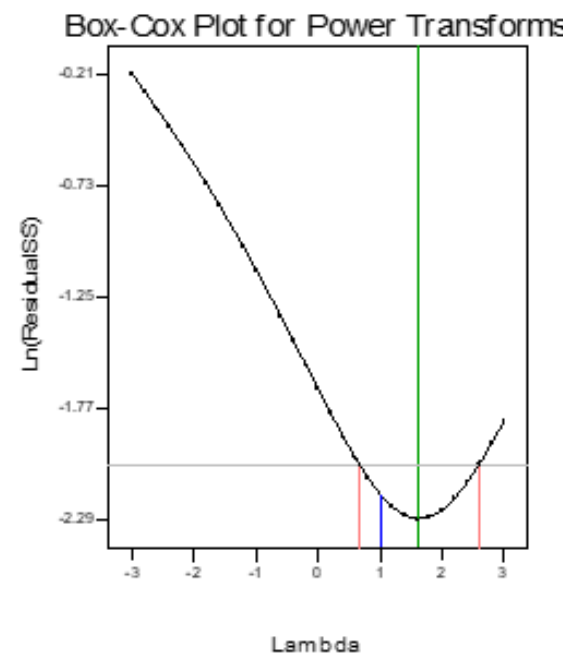

(b) Power transformation

Figure 3: Diagnostics graph.

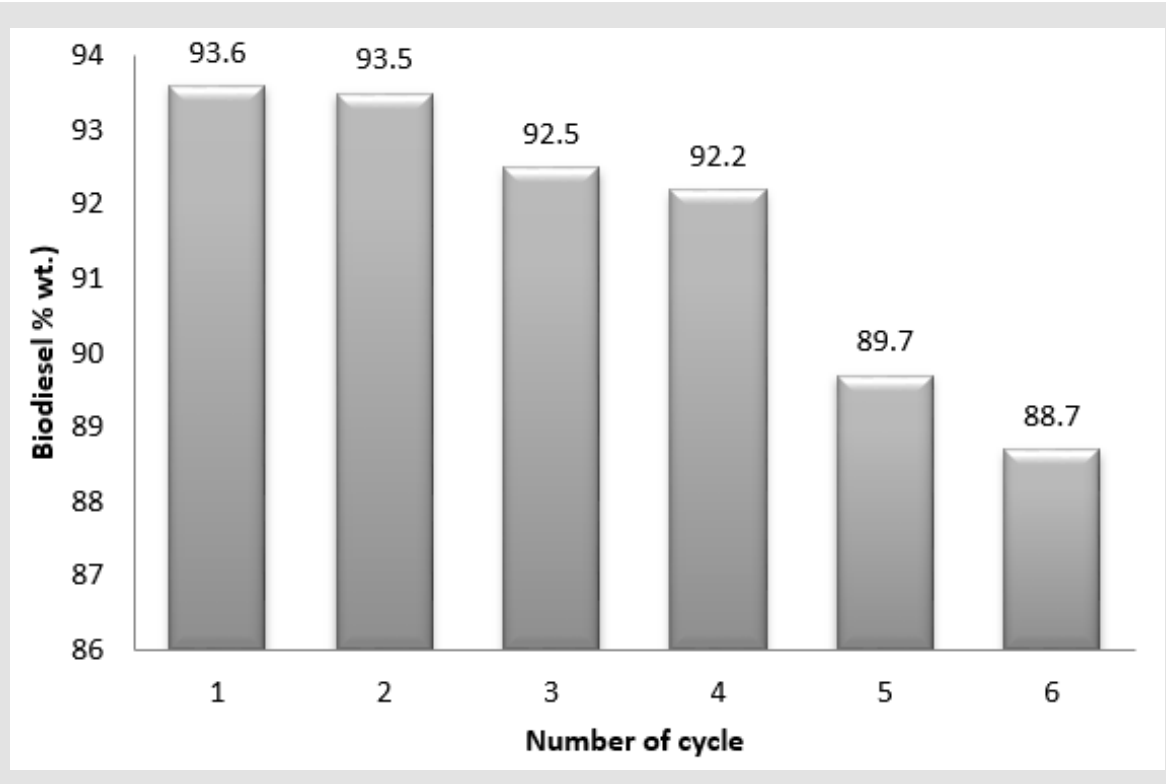

Figure 4: Catalyst recyclability test plot.

\section{Properties of the Mixed Oil and Biodiesel}

Method of AOAC were adopted to examine the properties of the blended oil and the product, the obtained results of the biodiesel were compared with the ASTM D6751 and EN 14214 biodiesel recommended standard (Table 6). It was observed that the decreased in the moisture content, density, viscosity, acid value, the iodine value, saponification, and the peroxide value of the blended oil to biodiesel was due to process transesterification. This confirmed that the synthesized product is consistent with biodiesel and the translation of blended oil complete transesterification reaction to biodiesel was achieved with insignificant resistance to flow and lessen internal drag in the engine. Further observation showed that the cetane number, the higher heating value (HHV), the API gravity, and the diesel index increased as blended oil was converted to biodiesel, this could be attributed to energy formation from viscous oil to low viscous oil. The high biodiesel yield obtained in this study could be attributed to due to decrease base consumption for neutralization. Based on cetane number, the higher the peroxide value, the better the cetane number and the decrease in ignition time $[31,40]$. The value of 4.34 meq $\mathrm{O}_{2} / \mathrm{kg}$ oil, can be attributed to the cetane number of 57.52 obtained. The higher heating value (HHV) of biodiesel is greater than that of blended oil which signify 
high heat of vaporization of water in the combustion of biodiesel. The American petroleum institute (API) gravity usually used to determine the weight of oil/petroleum in comparison with water, the value of 33.03 and 49.91 obtained for blended oil and biodiesel exhibited light oils. Diesel index which denotes the efficiency of the biodiesel as well as the ignition properties, the value obtained in this study were well within the required recommendation standard for biodiesel that can be used in I.C engine [41-44].

Table 6: Quality of mixed oil and biodiesel.

\begin{tabular}{|c|c|c|c|c|}
\hline Parameter & Mixed oil & Biodiesel & ASTM D6751 & EN 14214 \\
\hline Colour@27oC & Brownish & Light brown & - & - \\
\hline Density (kg/m3) @ 25oC & 860 & 780 & - & $860-900$ \\
\hline Viscosity @ 40oC/ (mm²/s) & 3.2 & 1.82 & $1.9-6.0$ & $3.5-5.0$ \\
\hline Moisture content (\%) & 0.002 & 0.001 & $<0.03$ & 0.02 \\
\hline$\%$ FFA (as oleic acid) & 0.82 & 0.16 & $0.40 \max$ & $0.25 \max$ \\
\hline Acid value (mg KOH/g oil) & 1.64 & 0.32 & $0.80 \max$ & $0.50 \max$ \\
\hline Iodine value (g I2/100g oil) & 84.79 & 56.4 & - & $120 \max$ \\
\hline Saponification value (mg KOH/g oil) & 187.92 & 132.4 & - & - \\
\hline Peroxide value (meq $\mathrm{O}_{2} / \mathrm{kg}$ oil) & 8.54 & 4.34 & - & 12.85 \\
\hline HHV (MJ/kg) & 40.46 & 43.16 & - & - \\
\hline Cetane number & 56.25 & 57.52 & $57 \mathrm{~min}$ & $51 \mathrm{~min}$ \\
\hline API & 33.03 & 49.91 & $39.95 \max$ & - \\
\hline Diesel index & 64.24 & 66 & $50.4 \mathrm{~min}$ & - \\
\hline
\end{tabular}

\section{Conclusion}

The study concluded that the ratio of blended oil produced low viscous oil, and the derived catalyst from the mixture of Cucurbita pepo, Musa acuminate and Citrullus lanatus peels powders, calcined at a temperature of $650^{\circ} \mathrm{C}$ for $3 \mathrm{~h}$, produced high $\mathrm{CaO}$ - base $(75.65 \%)$. Transesterification of blended oil to biodiesel was successfully carried out with maximum biodiesel yield of 97.20 (\%wt.). A statistical software with second order model analysis predicted biodiesel yield of 96.63 (\% wt.) at the following reaction time of $80 \mathrm{~min}$, the CMP amount of $3.53(\mathrm{~g})$, the reaction temperature of $90{ }^{\circ} \mathrm{C}$, and the $\mathrm{CH}_{3} \mathrm{OH} / \mathrm{OMR}$ of $9: 1(\mathrm{ml} /$ $\mathrm{ml}$ ), respectively. To validate this value, three experimental runs were carried out, and the average mean was determined as of 96.50 (\% wt.) was obtained which was close to the predicted value. Analysis of variance test confirmed the significant of variables with p-value $<0.0001$. Catalyst reusability test was immobile at the 4 th cycle due to loss of basicity that occurred due to leaching as a result of several recyclability during the reaction. Hence, the produced biodiesel conformed to biodiesel recommended standard, and the $\mathrm{CaO}$ catalyst could serve as promising economical feedstock for industrial application.

\section{Acknowledgment}

Authors acknowledge the effort of Teaching and non-teaching staff of the Department of Chemical/Petrochemical Engineering, Akwa Ibom State University. The efforts of all Technicians of the Research Institute, NASENI, Abuja is highly appreciated.

\section{Funding}

This work receives no fund from University, Private organization, or Government body.

\section{Conflict of Interest}

Authors declare that I have no known competing financial interests or personal relationships that could have appeared to influence the work reported in this paper.

\section{Code Availability}

Response surface methodology was applied for process optimization. The trial version Dx6 was used.

\section{Authors Contributions}

- Adepoju T. F, Conceptualization, Methodology, Software, Validation, Formal Analysis, Investigation, Resources, Data Curation, Writing-Original Draft, Supervision.

- Ukpong AA, Software, Validation, Formal Analysis, Investigation, Resources, Data Curation

Jimoh, R. O., Writing-Original Draft, Supervision.

\section{References}

1. Viriya-empikul N, Krasae P, Nualpaeng W, Yoosuk B, Faungnawakij K (2012) Biodiesel production over Ca-based solid catalysts derived from industrial wastes. Fuel 92: 239-244.

2. Foluso OA, Tolulope AA (2014) Methanolysis of Carica papaya seed oil for production of biodiesel. Journal of fuel 12: 324-332.

3. Hangun-Balkir Y (2016) Green biodiesel synthesis using waste shells as a sustainable catalyst with Camelina sativa oil. J Chem-NY, p. 1-10. 
4. Hadiyanto H, Sri PL, Widayat W (2016) Preparation and Characterization of Anadara Granosa Shells and $\mathrm{CaCO}_{3}$ as Heterogeneous Catalyst for Biodiesel Production. BCREC 11: 21-26.

5. Anwar M, Rasul M, Ashwath N, Nurun Nabi MD (2019) The potential of utilizing papaya seed oil and stone fruit kernel oil as a non-edible feedstock for biodiesel production in Australia-A review, Energy Reports 5: 280-297.

6. Milan DK, Ivica GD, Olivera SS, Petar MM, Dusan A, et al. (2018) Kinetic modeling and optimization of biodiesel production from white mustard (Sinapis alba L.) seed oil by quicklime catalyzed transesterification. Fuel 223: 125-139.

7. Seman DL (2008) Pork fat quality: A processor's perspective. Concurrent technical session II. Proceedings of the $61^{\text {st }}$ American Meat Science Association, p. 1-7.

8. Atabani AE, Silitonga AS, Badruddin IA, Mahila TMI, Majsjuki HH, et al. (2012) A comprehensive review on biodiesel as an alternative energy resource and its characteristics, Renew Sust Energ Rev 16: 2070-2093.

9. Jishy KJ, Sankar S (2016) Production of biodiesel from chicken fat, pork fat, and the combination of the two feedstocks. IJRME 4: 110-114.

10. Chinyere BE, Callistus NU, Okechuckwu DO (2017) Optimization of the methanolysis of lard oil in the production of biodiesel with response surface methodology. Egypt J Pet 26: 1001-1011.

11. Adepoju TF, Rasheed B, Olatunji MO, Ibeh MA, Ademiluyi FT, et al. (2018a) Modeling and optimization of lucky nut seed by pearl spar catalyzed transesterification 4: e00798.

12. Adepoju TF, Udoetuk EN, Olatunnbosun BE, Ibeh MA, Rasheed B (2018b) Evaluation of the effectiveness of the optimization procedure with the methanolysis of waste oil as a case study. S Afr J Chem 25: 169-175.

13. Zainal-Kifli AR, Shahida HK, Siti NMK, Gaanty PM (2018) Synthesis of alumina - $\mathrm{CaO}$-KI catalyst for the production of biodiesel from rubber seed oil. Malay J Analyt Scienc 2: 279-285

14. Prima AH, Abdullah A, Hadiyanto H (2019) Response surface optimization of biodiesel production from Nyamplug (Calophyllum inophyllum) oil enhanced microwave and Ionic liquid $+\mathrm{NaOH}$ catalyst. Period Poltech Chem Eng 63: 406-413.

15. Weimin Z, Yong-Gui P, Wuyang H, Haiming C, Hong Y (2019) Optimized ultrasonic assited extraction of papaya seed oil from Hainana/Eksotika variety. Food Science and Nutrition, pp. 2692-2701.

16. Subramaniapillai N, Govindaraj V, Muthusamy B (2019) Process optimization of Calophyllum inophyllum-waste cooking oil mixture for biodiesel production using Donax deltoids shells as heterogeneous catalyst. Sustain Environ Res 29: 2351-2362.

17. Khalil I, Aziz ARA, Yusup S, Heikal M, El-Adawy M (2017) Response surface methodology for the optimization of the production of rubber seed/palm oil biodiesel, IDI diesel engine performance, and emissions, Biomass Convers and Biorefin 7: 37-49.

18. Qiu F, Li Y, Yang D, Li X, Sun P (2011) Biodiesel production from mixed soybean oil and rapeseed oil, Appl Energ 88: 2050-2055.

19. Milano J, Ong HC, Masjuki H, Silitonga A, Chen HW, et al. (2018) Optimization of biodiesel production by microwave irradiation-assisted transesterification for waste cooking oil-Calophyllum inophyllum oil via response surface methodology, Energ Convers, and Manag 158: 400-415

20. Hadiyanto H, Inaya Y, Rafidha H (2018) Production of biodiesel from mixed waste cooking and castor oil. MATEC Web of conferences 156: 03056.

21. Falowo OA, Oloko-Oba MI, Betiku E (2019) Biodiesel production intensification via microwave irradiation-assisted transesterification of oil blend using nanoparticles from elephant -ear tree pod husk as a base heterogeneous catalyst, Chem Eng Process 140: 157-170.
22. Falowo OA, Omoniyi P, Ojumu TV, Betiku E (2020) Sustainable biodiesel synthesis from Honne-Rubber-Neem oil blend with a novel mesoporous base catalyst synthesis from a mixture of three agrowastes, Cataly 10: 1-24.

23. El-Gendy NS, Deriase SF, Hamdy A, Abdallah RI (2015) Statistical optimization of biodiesel production from sunflower waste cooking oil using basic heterogeneous biocatalyst prepared from eggshells. Egypt J Petrol 24: 37-48.

24. Cercado AP, Ballesteros F, Capareda S (2018) Ultrasound-assisted transesterification of microalgae using a synthesized novel catalyst. Sustain Environ Res 28: 234-239.

25. Mohammed SS, Paiko YB, Mann A, Ndamitso MM, Mathew JT, et al. (2014) Proximate, Mineral, and Anti-nutritional Composition of Cucurbita Maxima Fruits Parts. Nigerian Journal of Chemical Research 19: 54-63.

26. Oseni OA, Olarinoye CO, Amoo IA (2011) Studies on chemical compositions and functional properties of thorn apple (Datura stramonium L) Solanaceae. Africa Journal Food Science 5: 40-44.

27. Jacob AG, Etong DI, Tijjani A (2015) Proximate, Mineral, and Antinutritional Compositions of Melon (Citrullus lanatus) Seeds. BJR 2: 142151

28. Betiku E, Ajala SO (2014) Modeling and optimization of Thevetia peruviana (yellow oleander) oil biodiesel synthesis via Musa paradisiacal (plantain) peel as a heterogeneous catalyst: A case of artificial neural network vs. response surface methodology. Ind Crops Prod 53: 314-322.

29. Adepoju TF, Olatunji OM, Ibeh MA, Ekanem U, Olatunbosun BE, et al. (2020) Hevea brasiliensis (Rubber seed): An alternative source of renewable energy. Scientific African. Scientific African 8: e00339.

30. Adepoju TF, Ibeh MA, Ekanem U, Asuquo AJ (2020) Data on the derived mesoporous based catalyst for the synthesized of fatty acid methyl ester (FAME) from ternary oil blend: An optimization approach. Data in Brief 30: 105514

31. Adepoju TF, Eyibio UP (2016) Study on Oil Extraction from Citrullus lanatus (C. lanatus) oilseed and Its Statistical Analysis: A case of Response Surface Methodology (RSM) and Artificial Neural Network (ANN). CRJ 1: 28-36.

32. Minakshi G, Khairujjaman L, Atanu KP, Niran D, Mrutyunjay M, et al. (2020) Carica papaya stem: A source of versatile heterogeneous catalyst for biodiesel production and $\mathrm{CeC}$ bond formation. Renew Energ 147: 541-555.

33. Adepoju, TF, Olawale 0 (2015) Optimization and predictive capability of RSM using controllable variables in the Azadirachta indica oilseeds extraction process. IJCMR 3: 1-10.

34. ASTM D6751. Standard Test Method for Gross Calorific Value of Oil Water, Coal and Coke by the adiabatic Bomb Calorimeter from SAI Global.

35. EN 14214. European Committee for Standardization, describing the requirements and test methods for FAME.

36. Girish N, Niju SP, Begum KMMS, Anantharam N (2013) Utilization of cost-effective solid catalyst derived from natural white bivalve clamshell for transesterification of waste frying oil. Fuel 111: 653-658.

37. Wong EN, Krasae P, Nualpaeng W, Yoosuk B (2015) Biodiesel production via transesterification of palm oil using $\mathrm{CaO}-\mathrm{CeO}_{2}$ mixed oxide catalysts. Fuel 162: 288-293.

38. Trisupakitti S, Ketwong C, Senajuk W, Phukapak C, Wiriyaumpaiwong C (2017) Golden Apple Cherry Snail Shell as Catalyst for Heterogeneous Transesterification of Biodiesel, Brazilian J Chem Eng 35: 1283-1291.

39. Adepoju TF (2020) Optimization processes of biodiesel production from pig and Neem (Azadirachta indica A.Juss) seeds blend oil using alternative catalysts from waste biomass. Ind Crops Prod 149: 112334. 
40. Zuleta EC, Libia B, Luis AR, Jorge AC (2013) Oxidative stability of biodiesel and its impact on the deterioration of metallic and polymeric material: a review. J Brazil Chem Soc 23: 23-32.

41. Adepoju TF, Uzono RI, Akwayo IJ (2016) Modeling and Optimization of the Removal of Congo-Red Dye from Wastewater Using Agricultural Waste. JCEBE 1: 11-17.

42. Adewale A, Fabiano VP (2017) Underutilized Luffa cylindrica sponge: A local bio-adsorbent for the removal of $\mathrm{Pb}$ (II) pollutants from the water

\section{ISSN: 2574-1241}

DOI: 10.26717/BJSTR.2021.40.006483

Adepoju TF. Biomed J Sci \& Tech Res

(CC) This work is licensed under Creative

Submission Link: https://biomedres.us/submit-manuscript.php system. Beni-Suef University Journal of Basic and Applied Sciences 6: 118-126.

43. (1997) AOAC. Official methods of analyses of the Association of Official Analytical Chemists.

44. https://greengarageblog.org/15-advantages-and-disadvantages-ofusing-algae-as-a-biofuel.

$\begin{array}{ll}\text { BIOMEDICAL } & \text { Assets of Publishing with us } \\ \text { RESEARCHES } & \text { - Global archiving of articles } \\ \text { - Immediate, unrestricted online access } & \text { - Rigorous Peer Review Process } \\ & \text { - Authors Retain Copyrights } \\ \end{array}$

